\title{
The Need for Cognition on Earthquake Risk in China Based on Psychological Distance Theory
}

\author{
Shasha Li $\left(\mathbb{D},{ }^{1}\right.$ Guofang Zhai, ${ }^{2}$ Chenjing Fan $\left(\mathbb{D},{ }^{3}\right.$ Jing Chen, ${ }^{4}$ and Li Li ${ }^{1}$ \\ ${ }^{1} J a n g h o$ Architecture College, Northeastern University, Shenyang 110169, China \\ ${ }^{2}$ School of Architecture and Urban Planning, Nanjing University, Nanjing 210093, China \\ ${ }^{3}$ College of Landscape Architecture, Nanjing Forestry University, Nanjing 210037, China \\ ${ }^{4}$ Urban and Rural Development Research Center of Jiangsu Province, Nanjing 210036, China \\ Correspondence should be addressed to Chenjing Fan; fanchenj@qq.com
}

Received 27 August 2020; Revised 14 December 2020; Accepted 19 December 2020; Published 31 December 2020

Academic Editor: Jianhong (Cecilia) Xia; c.xia@curtin.edu.au

Copyright (C) 2020 Shasha Li et al. This is an open access article distributed under the Creative Commons Attribution License, which permits unrestricted use, distribution, and reproduction in any medium, provided the original work is properly cited.

\begin{abstract}
There is a high need for cognition on earthquake risk to improve the public's risk knowledge and risk awareness, so that they can make right decisions and take quick actions regarding mitigation measures and adjustments. In this study, search engine query data from the Baidu Index were extracted to reveal the information search behaviors of the Chinese public regarding the earthquake risk from 2010 to 2012. The data were also analyzed to discuss the characteristics of need for cognition on a nationwide scale and over the long term. The results showed that (1) graphic representations of need for cognition adhere to a "half-peak pattern" before and after earthquake events and (2) dimensions in psychological distance theory, such as temporal distance (time span between earthquakes), spatial distance, and social distance (geographic location) influence the need for cognition on earthquake risk that was the time and spatial discount effect. The implications for theory and practice regarding risk communication and management are discussed and concluded.
\end{abstract}

\section{Introduction}

People are inevitably exposed to risks as a part of life, and the consequences of these risks have become more and more serious with the development of modern infrastructure. How individuals respond and adapt to the risks they encounter has drawn the attention by academics, where it has been found that awareness of the public's perceptions and desire to learn more about risks serve as an important foundation for understanding different levels of risk-adaptation ability [1]. Up to the present, however, there have been few studies on how need for cognition (NFC) and information-seeking behavior led to differences in risk awareness and response. Related research has been limited to a one-dimensional focus on NFC in either time or space; few studies have involved both. This paper suggests that a more comprehensive understanding of how individuals' NFC regarding risks can help explain why individuals have different levels of risk perception, cognition, and response and, ultimately, promote more effective disaster reduction policies.
This study is presented in six parts. Following the introduction, Section 2 reviews the need for cognition of earthquake risk, information seeking and information search behavior, and psychological distance theory through the theoretical lens and then puts forward research hypotheses. Section 3 introduces the study area, the data collection, and data analysis techniques. The research findings are highlighted and discussed in Sections 4 and 5. The last section presents our conclusion and discusses the limitations and future studies of this research.

\section{Theoretical Background and Research Hypotheses}

2.1. The Need for Cognition of Earthquake Risk. Cognition is the process of acquiring knowledge and coming to a greater understanding of it through mental consideration. A dominant aspect of cognitive motivation, NFC, can be described as an eagerness to both find and engage in cognitive 
exercises. If for some reason the cognitive process is blocked or challenging, it is difficult for individuals to take certain actions. To this end, individuals low in NFC tend to avoid thinking and participating cognitive endeavors [2], while those high in NFC take pleasure in reflecting on information and tend to organize, assess, and expand on that information, making them more successful at completing cognitive tasks [3]. The conclusions of studies on NFC on the subject of risk can help psychologists to understand the feelings of people faced with risk and help risk managers to develop appropriate risk management plans on the basis of risk cognition research. Currently, because of difficulties in setting quantitative indicators and the heavy workload required to do so, studies on disease risk have been much more common than studies on disaster risk, despite the fact that natural disasters are a common occurrence in many parts of the world [4].

Earthquakes are one type of unpredictable and destructive natural disasters and often result in massive casualties and economic loss.A sudden earthquake event can make the public nervous, anxiety, and panic that may lead to the public's information anxiety for the disaster. In the process of human adaptation to earthquake risk, education on disaster mitigation is an important informational resource for reducing loss and saving lives following an earthquake [2]. However, NFC leads individuals to seek and understand information. Effective risk information helps an individual to judge earthquake risk situations, so that they can make accurate decisions and take quick actions regarding mitigation measures and adjustments. At present, studies on cognition and the behavior of individuals exposed to earthquake risk have used the psychometric paradigm and question-and-answer surveys to investigate individuals' behavior after an earthquake. Differences in the location, time, and rate of earthquakes experienced or known of by an individual or, historically, at a certain location had different effects on behaviors such as attention to earthquake risk, information processing, and risk response [5]. However, there have been no studies on NFC on earthquake risk that take into account both cognition and behavioral differences, and there has been no systematic exploration of the nature of NFC in this situation. Therefore, it is necessary to analyze the different levels of NFC using different groups at different places and times in order to draw firmer conclusions about the factors discussed above and the nature of NFC.

\subsection{Information Seeking and Information Search Behavior.} Information seeking has been defined as the process by which individuals "purposefully make an effort to change their state of knowledge" [6]. It is often used to solve problems and make decisions and, as such, is dependent on the input of new information. In this way, information seeking and NFC are related [7], as individuals with high NFC are more motivated to "change their state of knowledge" and to process information [8]. Risks have the characteristics of uncertainty and diffusion in time and space, and thus information on a specific risk affects individuals' risk cognition in that area [9]. In this context, information seeking can be seen as a part of an individual's personal choice to raise their own awareness and take selfprotective actions when faced with the uncertainty of risk. [10-13]. A previously established risk information seeking and processing model [10] showed that the risk information seeking process is prompted by perception of risk characteristics, affective response to risk, desire for knowledge of related policies, desire to improve response capacity and risk cognition, and personal characteristics that support information seeking. There is also ample evidence that risk information seeking and retention of that knowledge leads to positive outcomes [14-18].

Information search behavior is one aspect of information seeking [19]; it begins with a lack of knowledge or understanding [20] and the goal of reducing that knowledge gap [21]. Information search behavior is also related to NFC, as people high in NFC tend to find more information, generate more task-related cognitive responses to that information, and exert more cognitive effort searching for information than people low in NFC [22]. In recent years, with the development of the Internet and information technology (IT), more information is more readily available to more people and, as a result, the cognitive patterns of the general public have begun to change. The information search function provided by search engines helps members of the public to improve their cognition and make decisions more efficiently. With minimal cost and effort, individuals can acquire useful information; in fact, more than half of people using the Internet use search engines [23]. Current studies on NFC have shown that it is significantly and positively correlated with all web activities involving cognitive thought and that people high in NFC use the information services available through the Internet more than those who are low in NFC [24]. For example, people high in NFC are more likely to browse more web pages in pursuit of information and tend to retrieve this information when making decisions [25]. Level of NFC also has a significant effect on individuals' search effectiveness in terms of the precision with which they are able to obtain useful documents [26]. People high in NFC also perform better on tasks related to the information gained through this cognitive process.

These days, information on various types of risk is available on the Internet in the form of articles, news, and policies related to these risks [27] and it has been shown that the general public's use of search engines to seek information on risks is ever increasing [13] behavior that reflects the information seekers' NFC on risks. Because search engines record search data, scholars have been able to use search archives in studies of risk management. For the moment, the search engine data has commonly been used in health risk, targeting the earlier monitoring and forecasting of disease risk, such as influenza epidemics [28], dengue fever [29], Ebola virus [30], Aids [31], Hepatitis B [32], Gastroenteritis [33], H7N9 [34], erythromelalgia [35], and hand-foot-and-mouth disease [36]. However, the search engine data was seldom used in natural disaster risk, and the studies currently available are about the typhoon risk [37], Hurricane risk [38], and earthquake risk [39]. The primary research methodology employed in studies of this 
type is search query data mining, which can be used to summarize the differences between individuals' cognition of risk and the process of meeting their NFC as well as to reveal macroscopic social phenomena. This method has captured the attention of risk scholars in recent years because it allows researchers to use a large amount of data in a manner that is cheaper, easier, and more conclusive than sampling [40].

2.3. Psychological Distance Theory. Psychological distance theory can explain why individuals from different places and different times make different decisions and exhibit different behaviors and are concerned about the same event [40, 41]. Psychological distance incorporates four crucial dimensions: temporal distance, spatial distance, social distance, and uncertainty (probability distance). Temporal distance describes the perceive on the distance between event occurrence time and this moment [42]. Research showed that the earlier the timing of events, the less attention they get. The judgment of severity to environmental risk is minified as time goes on. Moreover, it is believed that the closer you are to the source of the risk, the more threatening it is by the environmental risk. Therefore, spatial distance can minify the perceived level of subjective risk [43]. The social distance stresses close and distant relationships between people. The social reference origin is the self. With further social distance, people may reduce emphasis on the event happening to other people [44]. Normally, people are just concerned about the close relationship with themselves, such as their families and friends, and choose to ignore the distant relationship with themselves, such as the strangers. The probability distance means the perceived size of disaster event occurrence likelihood by the individual [45].

The public subjective judgment to disaster risk is affected by the psychological distance. Psychological distance can make the subjective risk perception magnify or minify. The concept of psychological distance was introduced to the fields of mass media, linguistics, sociology, pedagogy, finance, human geography, and environmental risk. The research in environmental risk was concentrated in climate change [40], nuclear waste leak event [46], greenhouse effect [47], soil contamination [48], water contamination [49], haze [50], and typhoon disaster risk [51].

However, there is currently quite limited evidence examining psychological distance within the domain of earthquake risk in relation to NFC. There is a variety of disparate evidence that speaks to these issues individually [5], which can be used to create some context for this study. For example, taking the Wenchuan earthquake (May 12th, 2008, $M=8.0$ ) as an example, Sun et al. found that public concern about earthquakes noticeably decreased at two time points during their questionnaire study-one week and three months after the earthquake [52]. Xu et al. found that the emergency response of the public in the Nanzheng county of Shaanxi province improved after an earthquake when, following the quake, a slight tremor was felt and the public reacted according to what they had learned from the quake itself [53]. Similarly, $\mathrm{Su}$ et al. compared public risk cognition before and after an earthquake in Beijing and found that public awareness of disaster prevention and response improved after the quake occurred by comparing the risk cognition before and after the earthquake in Beijing [54]. In terms of psychological distance, Jia et al. found that people in the areas hardest-hit by earthquakes had a significantly higher risk perception than areas hit less often [55]. Li et al. also found earthquake information significantly affected public mood and mindsets in the areas hardest-hit by an earthquake but made little effect in other areas [56]. One reason for this may be that, as suggested by Shani et al., those with lower-level construal are consequently more motivated to seek information [57]. In a study on climate change, Spence et al. argued that lower psychological distance can be linked to increased levels of concern and a higher likelihood of taking action and suggested that the salience of risk information could be influenced by psychological distance of those receiving it, impacting their risk perceptions and behavioral intentions [41].

2.4. Current Research Data and Methods. According to current research, psychological distance, influenced by earthquakes at different locations and times, might also affect individuals' levels of NFC on earthquake risk, resulting in differences in cognition regarding earthquakes, particularly in the moment a quake occurs. Ideally, to thoroughly explore the role of NFC in disaster risk, a large-scale, longterm survey method should be used, but because this is not feasible due to manpower and material demands and because levels of NFC are hard to quantify, need of new research methods is required.

This paper proposed a new research method that utilizes search engine data. Search engine query data for the keyword "earthquake" was used to create an index for researching public NFC on earthquake risk. When the individuals have NFC on earthquake risk, they have a desire to seek information and so log onto the Internet to search for earthquake information. Searching for information with terms such as "earthquake," "XX earthquake," "how to protect oneself when earthquakes occur," "earthquake insurance," "what is missing after the XX earthquake," and others containing the word "earthquake" is an important method for individuals to meet their NFC and improve their level of cognition. Therefore, the volume of searches and the number of people who used the Internet to access risk information during earthquake events at different places and times can be used to quantify the level of NFC on earthquake risk and can be considered to reflect the different levels of NFC at different places and times.

Taking China as research area, this paper analyzes Baidu search engine query data for the keyword "earthquake" from 2010 to 2012 by province, discusses the influence characteristics of four dimensions in psychological distance theory on NFC, and, lastly, explains these characteristics using. The findings of this research can help policy maker to enact efficient risk management policies based on published, scientific risk information and help the public to make more accurate judgments during earthquakes disaster losses can be mitigated. 
2.5. Hypotheses. According to the conclusions of recent researches on individuals' reactions to earthquakes, both the severity of an earthquake and a closer psychological distance caused individuals to be more concerned about the disaster. With this in mind, this paper holds the hypotheses presented below.

Based on prior researches to the temporal distance, if an earthquake has just happened, the public may be concerned more about and pay more attention to the risk. Then, as time goes on, the public will gradually lose concern for the risk:

Hypothesis 1: public NFC on earthquake risk will increase directly after an earthquake but will then decrease until the next earthquake.

Based on prior researches to social distance and spatial distance, the public may pay more attention to the risks that affect their own interests and show the most concern about the earthquake risk in hardest-hit areas and level of concern will decrease as the distance from these areas increases:

Hypothesis 2a: the segment of the public with the highest NFC on earthquake risk will be those in the hardest-hit areas.

Hypothesis 2b: public's NFC on earthquake risk will decrease as distance from the hardest-hit areas increases and, due to this, domestic or spatial autocorrelation exists.

Based on the uncertainty (probability distance) dimension of the psychological distance theory, we have the following:

Hypothesis 3: public's NFC on earthquake risk will be higher in places where earthquakes have occurred more frequently throughout history, and a positive correlation will exist between earthquake frequency and NFC.

\section{Materials and Methods}

3.1. Study Area. This paper took China as a study area because seismic activity occurs often there. It is located between two significant earthquake belts, referred to as the Eurasian earthquake Zone and the Pacific Ring of Fire, and is pressed upon from the East by the Pacific plate and from the South by the plate of the Indian and Philippines Sea. The number of earthquakes in China accounts for approximately one-fourth of those in the world each year, and China is also one of the areas that sustains the most earthquake damage [58]. Geographically, 22 provincial capitals and two-thirds of major cities with a population of more than one million are in the high-risk areas for earthquake [59]. Except Guizhou and Zhejiang province, all the provinces have experienced earthquakes of magnitude 6.0 or higher. 19 provinces had recorded earthquakes of 7.0 magnitude.

3.2. Data Collection. This paper used three sources of data: search engine query data, the number of Internet users, and earthquake statistics.
3.2.1. Search Engine Query Data. The search engine query data was collected from each province in China using the Baidu index (http://index.Baidu.com/) and compiled by term. The Baidu index is an online application produced by Baidu, China's largest search engine company. Users can query the index for the number of times a keyword has been searched by the public in any place and at any time. The number of times a keyword is searched in a place (locations are based on the searchers' IP) reflects the level of NFC on a specific event in that place. Although the query data from Baidu cannot accurately represent populations or to be applied in statistical algorithms, it can be used to generalize tendency [60] and, in that respect, this data exhibits huge advantages over questionnaire data. The Chinese language is very widely used in information searches in China, and Baidu is the largest Chinese-language search engine; therefore, it can be inferred that using the Baidu index to study the characteristics of NFC on earthquake risk is both reasonable and achievable.

From the Baidu index, search engine query daily data for the keyword "earthquake" was collected from China's 31 provinces and municipalities from January 1, 2010 to December 31, 2012, and April 2013 and August 2014 (excluding Hong Kong, Macao, and Taiwan regions because there was no data for these areas and data from the Xinjiang province from January 2010 to May 2010 due to data errors).

3.2.2. The Number of Internet Users. The number of Internet users in each province at the end of 2009-2014 came from the 25th, 27th, 29th, 31st, 33rd, and 35th editions of The Statistical Report on Internet Development in China [61].

3.2.3. Earthquake Statistics. The statistics for earthquake events came from the earthquake catalogue, published by the China Earthquake Network Center (CENC) (http://www. csndmc.ac.cn/newweb/data.htm). The statistics used include the locations and dates of all earthquakes with a magnitude larger than 4.0 in China and larger than 7.0 in other countries that occurred from January 1st, 1970, to December 31st, 2012.

3.3. Data Analysis Techniques. The method employed to research NFC on earthquake risk using search engine query data is put forward by the author and has been developed for this specific case, based on the fact that NFC is significantly and positively correlated with information search behavior. One key challenge was defining the frequency of earthquake risk search, which was determined by eliminating the differences between the population bases in the provinces; another was using models to test the hypothesis.

\subsubsection{Defining of the Frequency of Earthquake Risk Search}

(1) Estimated Percentage of the Population That Used the Internet. To eliminate the differences in population base between the provinces, the number of people who used the Internet must first be estimated. To do so, an exponential algorithm was used to estimate this number on any given day: 


$$
n_{i d}=n_{i(y-1)} \times\left(365 \sqrt{\frac{n_{i y}}{n_{i(y-1)}}}\right)^{d^{\prime}},
$$

where $n_{i d}$ is the number of people who used Internet in $i$ province at $d$ day; the unit is ten thousand people; $n_{i y}\left(n_{i 2009}\right.$, $\left.n_{i 2010}, n_{i 2011}, n_{i 2012}, n_{i 2013}, n_{i 2014}\right)$ is the number of people who used Internet in $i$ province at the end of the years 2009, 2010, 2011, 2012, 2013, and 2014, obtained from The Statistical Report on Internet Development in China; $d$ is the sequence number of the date, where $d=1$ means January 12010 , $d=1096$ means 31 December 2012, and $d^{\prime}$ is the number of days from January 1st in $y$ year. For example, the calculation for the population $n_{i d}$ on January 3rd, 2010, is $n_{i 2009} \times\left(\sqrt[365]{n_{i 2010} / n_{i 2009}}\right)^{3}$.

(2) The Frequency of Earthquake Risk Information Search. This paper defined the frequency of earthquake risk information search (FSE) on $d$ day as follows:

$$
F_{i d}=\frac{c_{i d}}{n_{i d}}
$$

where $F_{i d}$ is the FSE by day and reflects the level of NFC on earthquake at $d$ day in $i$ province (unit: times of search/ten thousand people a day), and the higher $F_{i d}$ is, the higher NFC on earthquake risk in $i$ province at $d$ day is. $c_{i d}$ is the search engine query data for the keyword "earthquake" on $d$ day from the Baidu index (unit: times of search/a day).

3.3.2. Analytical Methods. Three methods of analysis were used in accordance with the three hypotheses given above: (1) the analysis of NFC variation over time, (2) the analysis of NFC variation by location, and (3) a discussion of the relationship between NFC and the historical frequency of earthquakes in a given area. Additionally, unexpected data and results are also addressed.

(1) Method of Analysis for Variation of NFC over Time. To verify Hypothesis 1, a case study method was employed using pass earthquakes: the Yushu earthquake (April 14th, 2010, $M=7.1$, Qinghai Province), the Yaan earthquake (April 20 ${ }^{\text {th }}$, 2013, $M=7.0$, Sichuan Province), and the Ludian earthquake (August $3^{\text {rd }}, 2014, M=6.5$, Yunnan Province) were selected as case study subjects because they had the highest FSE in the years 2010 to 2014. To analyze variation over time, the average countrywide values of FSE for a total of 9 days (2 days before the earthquake and 7 days after) were compiled. The average countrywide values of FSE were calculated as follows:

$$
\overline{F_{d}}=\sum_{i=1}^{i=31} \frac{F_{i d}}{31}
$$

(2) Method of Analysis for Variation of NFC by Location. To verify Hypothesis $2 \mathrm{a}$, this study used the epicenters and the provinces with the highest FSE values during the three earthquakes listed above. To verify Hypothesis $2 \mathrm{~b}$, A spatial autocorrelation method was used to analyze FSE by location with reference to the three earthquake events. An index of the average FSE by week was used because of the longer timescale and the slightly different amounts individuals of time spent online over the course of a week. The average FSE in week $w$ in $i$ province is given by

$$
F_{i w}=\sum_{d}^{d+6} \frac{F_{i d}}{7} .
$$

Accordingly, the average countrywide value of $\overline{F_{w}}$ is

$$
\overline{F_{w}}=\sum_{i=1}^{i=31} \frac{F_{i w}}{31} .
$$

Moran's I (formula (6)) is a weighted correlation coefficient used to detect departures from spatial randomness in geostatistical theory and to determine whether neighboring areas are more similar than would be expected under a null hypothesis [62]:

$$
I=\frac{n}{S_{0}} \frac{\sum_{i=1}^{n} \sum_{j=1}^{n} W_{i j} z_{j} z_{i}}{\sum_{i=1}^{n} z_{i}^{2}}
$$

Here, Moran's I for $F_{i w}$ in week $w$ can be calculated using the following formula:

$$
I=\frac{31}{S_{0}} \frac{\sum_{i=1}^{31} \sum_{j=1}^{31} W_{i j} z_{j w} z_{i w}}{\sum_{i=1}^{n} z_{i w}^{2}},
$$

where $W_{i j}$ is a spatial weight denoting the strength of the connection between the provinces $i$ and $j$. If the province $i$ is adjacent to $j$, then $W_{i j}$ equals 1 ; otherwise, $W_{i j}$ equals 0 and $z_{i}$ is FSE in province $i$ centered around the mean FSE (using $\left.z_{i w}=F_{i w}-\bar{F}_{w}\right)$. And $S_{0}$ is the sum of the spatial weights. The value of Moran's $I$ will lie within the range -1 to 1 for normalization. $I>0$ indicates that the distribution of FSE is positively related to geographic distance, which implies that the FSE value within a certain region is higher than others and decreases with distance. If $I<0$, the distribution of FSE is random or negatively related to geographic distance, which implies that no significant spatial differentiation exists. By comparing earthquake events and Moran's I over time, $\mathrm{H} 2$ can be tested.

(3) The Relationship between NFC and the Historical Frequency of Earthquakes. Because NFC on earthquake risk may be variable, the average FSE over the long term, which reflects NFC on earthquake risk in a given place, can be compared with the historical frequency of earthquakes to verify Hypothesis 3. Here, the number of earthquakes in recorded history (from January 1st 1970 to December 31st 2012) in each province and the province's average FSE were analyzed for correlations over the seven years from 2010 to 2012 (1096 days). The FSE in $i$ province over 7 years is

$$
\overline{F_{l}}=\sum_{d=1}^{d=1096} \frac{F_{i d}}{1096} .
$$

(4) Analysis of Unexpected Data. Since this research was an exploratory study using an FSE index to revealed NFC on 
earthquake risk, data exceptions were anticipated and these will be addressed along with the other results.

\section{Results}

4.1. Hypothesis 1. Hypothesis 1 holds that public NFC on earthquake risk will increase after an earthquake and then decrease until the next earthquake. Figure 1 shows $\overline{F_{d}} 2$ days before and 7 days after the Yushu earthquake, the Yaan earthquake, and the Ludian earthquake. It can be observed that the curve of $\overline{F_{d}}$ is a typical half-peak pattern-flat before the earthquake, rising sharply during the earthquake, and decreasing as time goes on. This variation reflects that the NFC on earthquake risk increases when people perceive earthquakes as being closer to them in time, supporting Hypothesis 1.

4.2. Hypothesis 2. Hypothesis 2 is related to psychological distance in the dimensions of geography and society. Figures 2 to 4 show $F_{i d}$ for the Yushu earthquake, the Yaan earthquake, and the Ludian earthquake 2 days before and 7 days after. Figure 5 shows $F_{w}$ and Moran's $I$ for $F_{i w}$ over time.

Hypothesis 2 a holds that the population with the highest NFC on earthquake risk is the one in the hardest-hit area after an earthquake. In the example of the Yushu earthquake, $F_{i d}$ of Tibet was the highest on the day earthquake occurred and the following day. It was only afterward that the Qinghai provinces, which were closest to earthquake epicenter, had the highest $F_{i d}$ (Figure 2). In the example of the Yaan earthquake, apart from Sichuan, on April 20th and 21st, $F_{i d}$ of Chongqing and Shaanxi, which were the closest to the epicenter, were ranked first and second (Figure 3 ). In the example of the Ludian earthquake, apart from Yunnan, on August 3rd and 4th, $F_{i d}$ of Sichuan and Tibet, which were the closest to the epicenter, were ranked first and second (Figure 4). Based on these results, Hypothesis 2a was supported. During verification, it was found that the Beijing and Tianjin always had a higher $F_{i d}$ after any earthquake, which will be discussed below.

Hypothesis $2 \mathrm{~b}$ holds that NFC on earthquake risk is spatially autocorrelated after an earthquake. Figure 5 shows the rise of Moran's $I$ for $F_{i w}$ and the occurrence of earthquakes $(M>4.0)$ within China was closely related between 2010 and 2012, indicating that the FSE demonstrated spatial autocorrelation in the case of domestic earthquakes. Thus, Hypothesis 2b was supported.

Analysis of the weeks when the earthquakes occurred and when Moran's I approached zero suggested the following:

(1) The spatial correlation of FSE was not significant in those weeks because the earthquakes in question had occurred offshore or because too many earthquakes had occurred in a short period of time (see Exception Data A in Figure 5).

(2) Some earthquakes that occurred aboard did not influence the spatial correlation of FSE in China.
(3) The week of February 15th, 2010, to February 21st, 2010, had a relatively high FSE, but a negative spatial correlation of FSE; the only earthquake that occurred was in the Jilin province (February 18th, 2010, $M=6.5$ ). This exception will also be discussed below (see Exception Data B in Figure 5).

4.3. Hypothesis 3. Hypothesis 3 holds that public's NFC on earthquake risk will be higher in areas where earthquakes have historically occurred more frequently. Figure 6 and Table 1 show the locations earthquakes in recorded in history over the last 42 years (from January 1st, 1970, to December 31st, 2012), indicating that NFC on earthquake risk was high in Tibet, Beijing, and Tianjin provinces and low in the Guangdong, Guangxi, and Hunan provinces. Comparing the frequency of earthquakes over 42 years, most provinces met Hypothesis 3. However, NFC in Beijing, Shanghai, and Tianjin, where few earthquake events had been recorded, was relatively high. Therefore, Hypothesis 3 was not supported.

4.4. Unexpected Data. During the process of validating Hypothesis 2b, the week February 15th, 2010, to February 21st, 2010, had a relatively high FSE but a negative spatial correlation of FSE; only one earthquake occurred. From analyses of this unexpected data, it was found that the rise in FSE was not caused by the earthquake but instead by an earthquake rumor in the Shanxi province [63]. Because this rumor was widespread, the public believed there would an earthquake on February 21st, 2010. Figure 7 shows the FSE before and after the Shanxi earthquake rumor event.

\section{Discussion}

Our research has provided the opportunity for in-depth analysis of the nature of the NFC on earthquake risk and, in particular, analysis of trends in public NFC on earthquake risk in China. In contrast to previous discussions of earthquake risk, our data indicates that the NFC on earthquake risk is influenced by psychological distance and that, generally, closer psychological distance was related not only to higher concern [41] but also to higher NFC on earthquake risk. However, NFC on earthquake risk also varied by demographic, which complicated explanations of the levels of NFC in some areas using the psychological distance theory.

\subsection{Theoretical Implications}

5.1.1. NFC on Earthquake Risk by Educational Level. In relation to educational level, those who were highly educated demonstrated a stronger NFC on earthquake risk, which is similar result on the correlation between NFC and education found in various studies on psychology, catastrophology, and risk management [2]. This is because those who are highly educated are also associated with high intelligence, and, therefore, they are likely to actively search for and gather sufficient information before solving with problems 


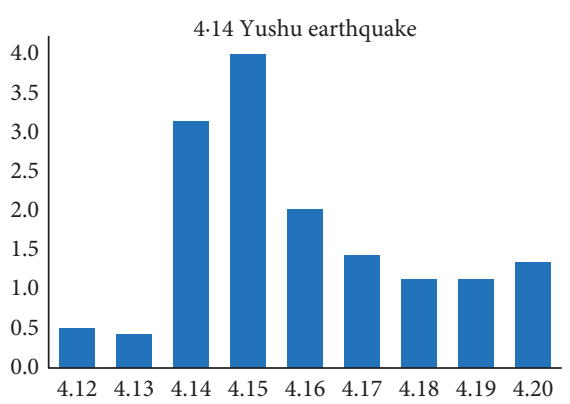

(a)

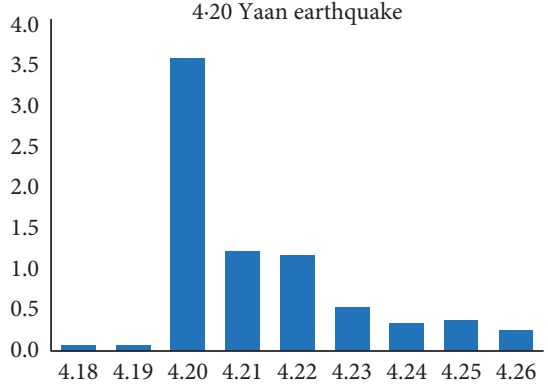

(b)

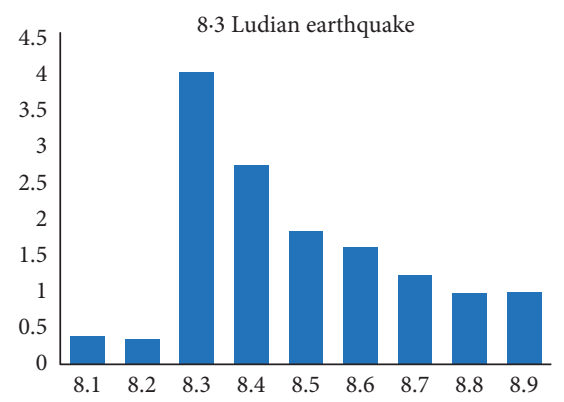

(c)

Figure 1: Time series of $\overline{F_{d}}$ before and after the Yushu earthquake, the Yaan earthquake, and the Ludian earthquake.

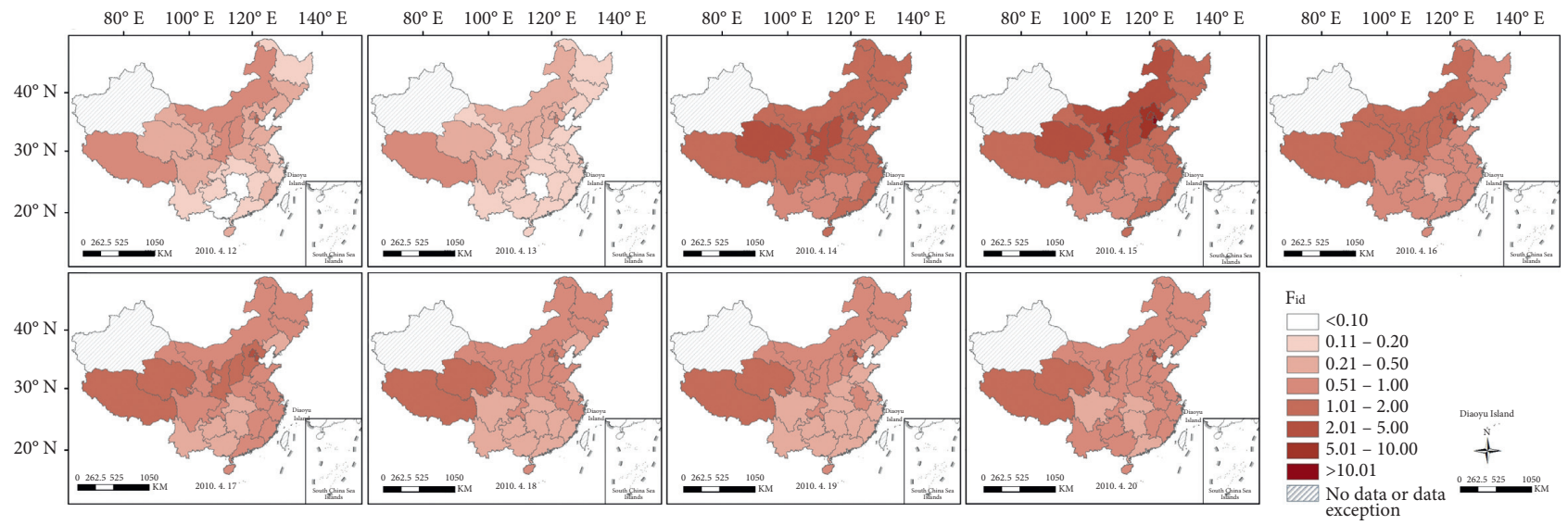

FIgURE 2: $F_{i d}$ before and after the Yushu earthquake (4/12/2010-4/20/2010).

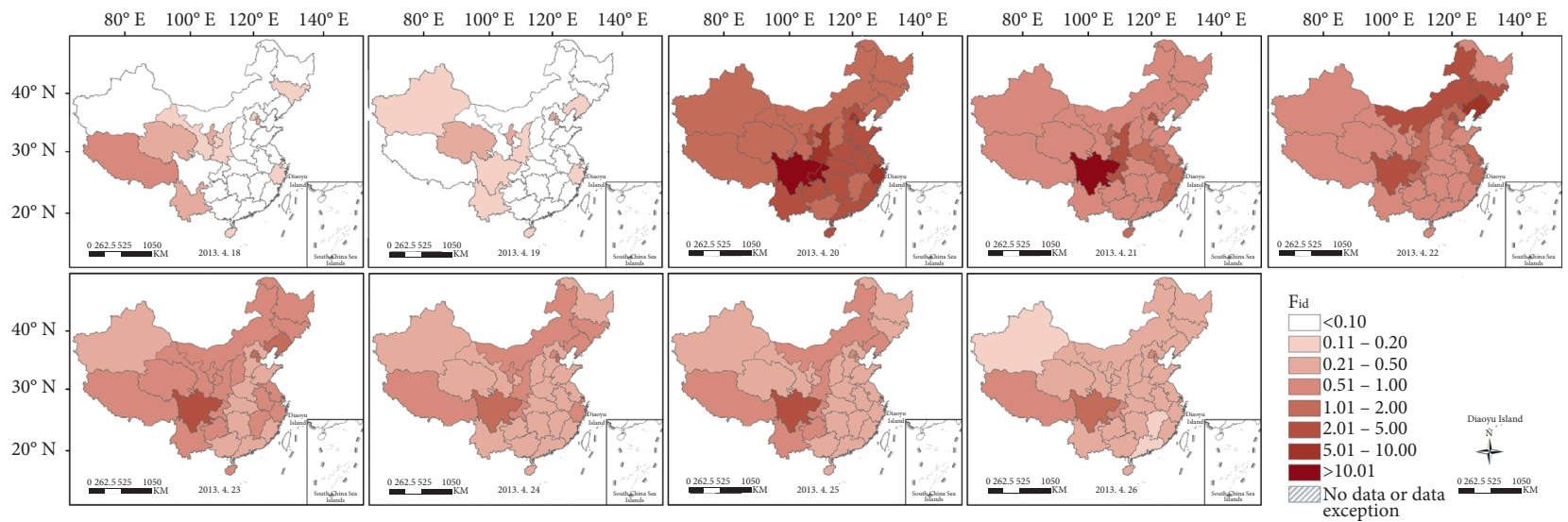

FIGURE 3: $F_{i d}$ before and after the Yaan earthquake (4/18/2013-4/26/2013). 


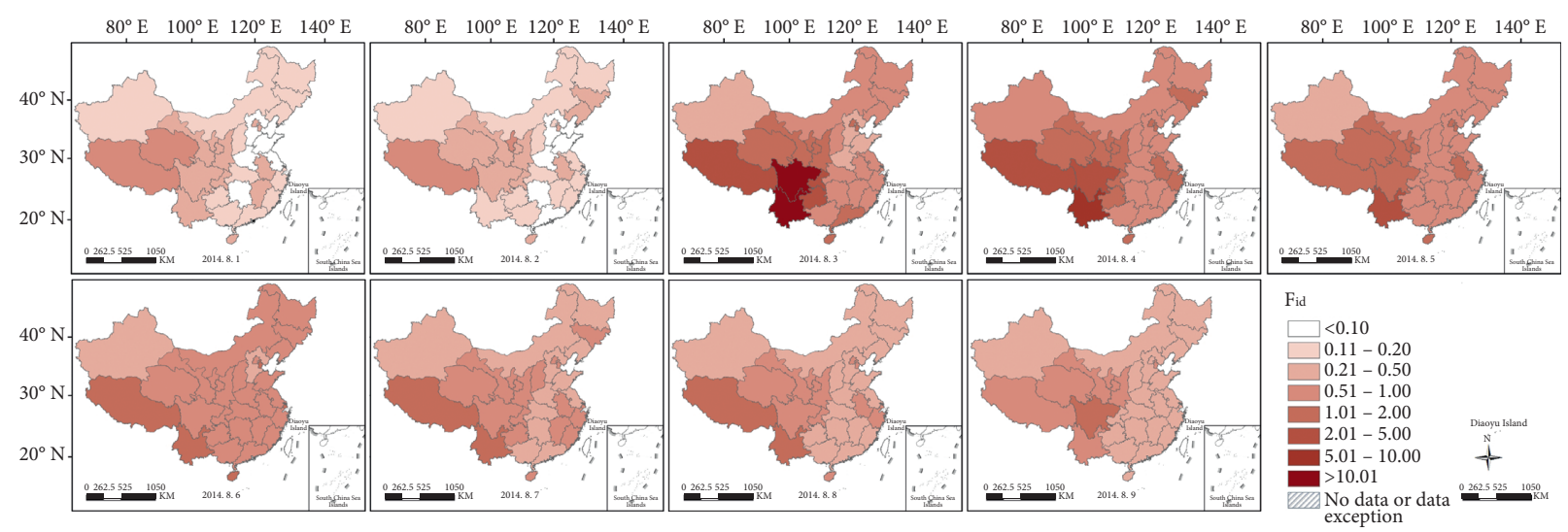

Figure 4: $F_{i d}$ before and after the Ludian earthquake (8/1/2014-8/9/2014).

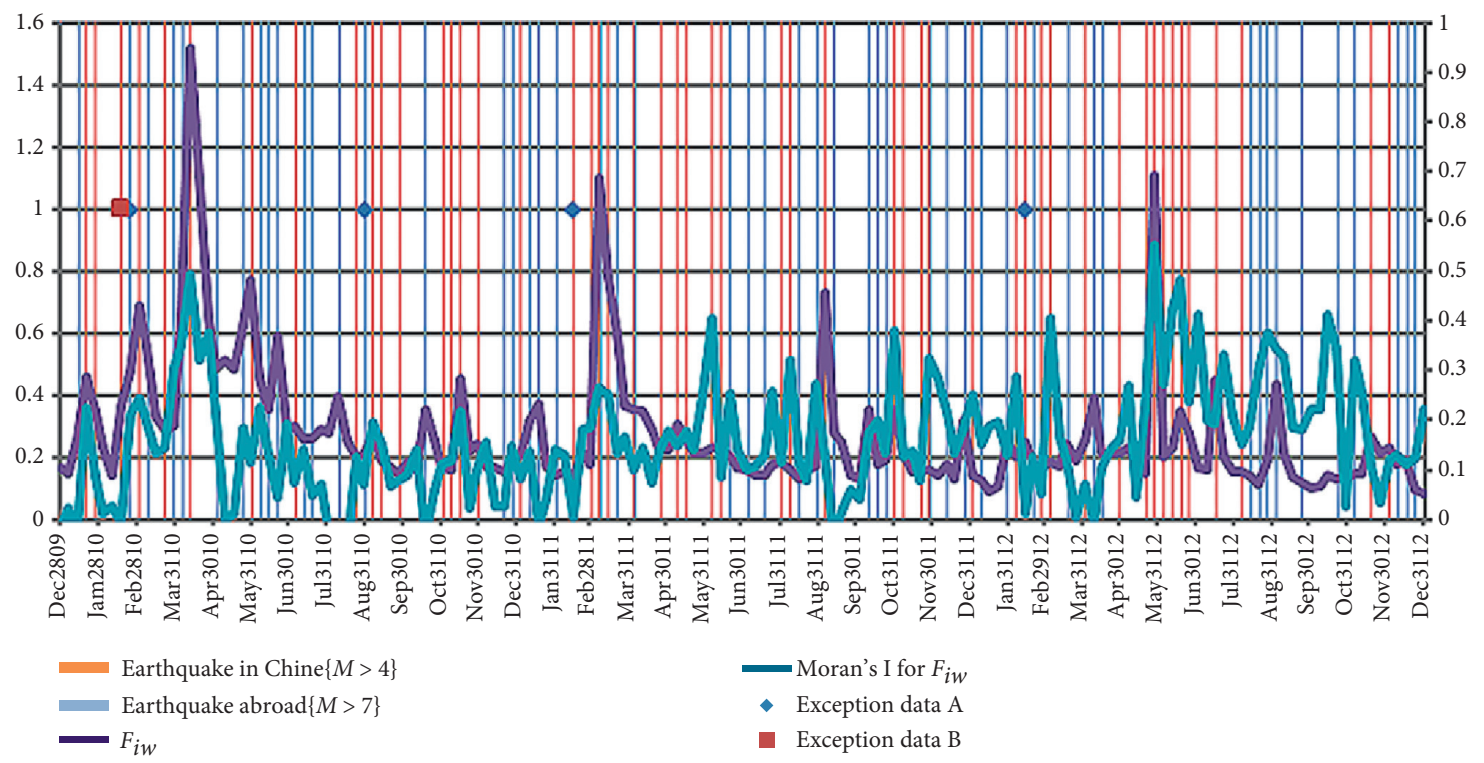

Figure 5: Time series of $F_{i w}$ and Moran's I for $F_{i w}$ (2010-2012).

or addressing the unknown. Thus, by nature, they have more need for information on disaster than those with lower educational level.

On the above statements, it was also found that an area where people were more highly educated in general exhibited a higher NFC and had faster responses to earthquakes. For example, the capital, Beijing, along with the Tianjin and Shanghai are the areas of China where the population has higher educational levels. On the day of the Yushu earthquake, Beijing and Tianjin had the highest FSE. Therefore, this paper holds the reason why Hypothesis 3 was not supported for the difference in social development. Beijing, Tianjin, and Shanghai are the largest municipalities in China, where the economy, education, and culture are more developed. Thus, (1) people have a higher NFC on earthquake risk in these provinces, even when there is no direct earthquake risk (Figure 6) and (2) these areas have a higher NFC than those where earthquakes have recently occurred.
5.1.2. The Influence of Temporal Distance to NFC on Earthquake Risk. From the examples of variation in $F_{i d}$ shown in Figure 1, it can be concluded that the variation curve of NFC on earthquake risk demonstrates a "half-peak pattern" during an earthquake-low before the earthquake, high on the day of the quake, and decreasing as time goes on. This time, characteristic confirms previous research. After the event, with time elapsing, the severity of the risk perceived by the public will be reduced, that is, time discount effect $[46,48,50,51]$. This is in contrast to the "peak-pattern" found by earlier studies, which were focused on predictable disasters, such as torrential rain and hurricanes [37], This difference can be explained using psychological distance theory: when a predictable disaster is about to happen, the people will feel close to the disaster in terms of temporal distance because of the date the risk is impeding. Therefore, NFC increases gradually up to the disaster as the temporal distance increases. After the disaster, NFC gradually decreases, producing the "peak-pattern." But with unpredictable disasters like earthquakes, people do not know when they are 


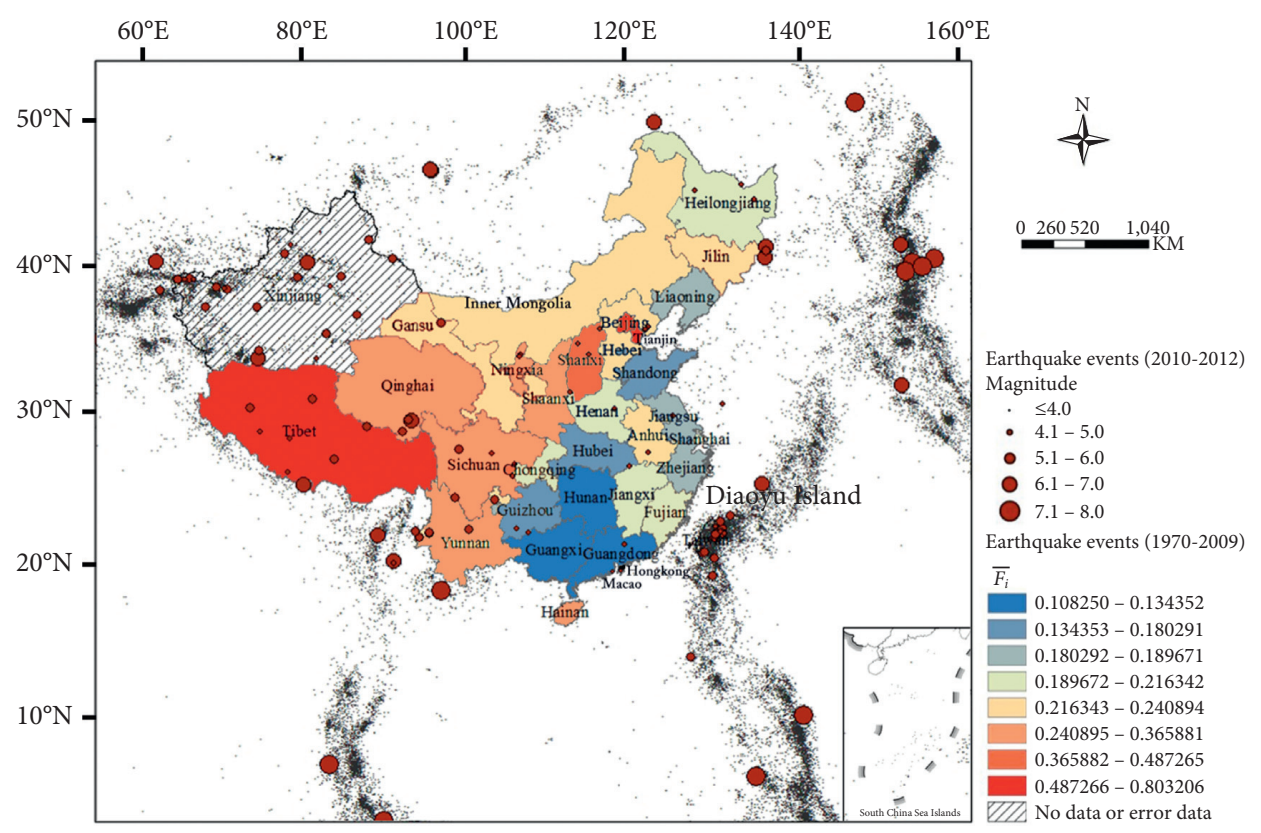

Figure 6: $\overline{F_{1}}$ and earthquake events (1970-2012).

TABLE $1: \overline{F_{l}}$ and yearly earthquake frequency.

\begin{tabular}{lcc}
\hline Name of province & $\overline{F_{l}}$ & Earthquake frequency \\
\hline Tianjin & 0.5820 & 0.6977 \\
Beijing & 0.5990 & 0.0930 \\
Shanghai & 0.3093 & 0.0233 \\
Tibet & 0.8032 & 37.6047 \\
Shanxi & 0.4378 & 2.2093 \\
Qinghai & 0.3659 & 20.4651 \\
Yunnan & 0.3181 & 23.3256 \\
Shaanxi & 0.3140 & 0.9070 \\
Sichuan & 0.3511 & 33.3488 \\
Ningxia & 0.2873 & 1.5349 \\
Hainan & 0.2780 & 0.4651 \\
Gansu & 0.2409 & 6.4419 \\
Anhui & 0.2333 & 0.3256 \\
Inner Mongolia & 0.2282 & 4.6047 \\
Hebei & 0.2234 & 6.8605 \\
Jilin & 0.2222 & 0.6047 \\
Fujian & 0.2163 & 0.7907 \\
Chongqing & 0.2136 & 0.8140 \\
Henan & 0.2109 & 0.5116 \\
Heilongjiang & 0.2078 & 0.9302 \\
Jiangxi & 0.2063 & 0.4419 \\
Jiangsu & 0.1897 & 0.4419 \\
Zhejiang & 0.1867 & 0.4186 \\
Liaoning & 0.1803 & 1.5581 \\
Guizhou & 0.1764 & 1.2558 \\
Hubei & 0.1732 & 0.4419 \\
Shandong & 0.1701 & 0.4419 \\
Guangdong & 0.1244 & 0.6977 \\
Guangxi & 0.1344 & 0.5116 \\
Hunan & 0.1083 & 0.0698 \\
\hline Note & $(e x e t$ & 5 \\
\hline & 0.319 \\
\hline
\end{tabular}

Note. ${ }^{*} r=0.54 ;{ }^{*} r=0.76$ (except Beijing, Tianjin, and Shanghai).

about to occur, and, in the time before disaster strikes, their temporal distance remains large because it is tied to whenever the last earthquake occurred. Therefore, directly after an earthquake, their temporal distance decreases sharply while NFC rises swiftly, resulting in a curve that presents a "half-peak pattern."

5.1.3. The Influences of Spatial Distance and Social Distance to NFC on Earthquake Risk. In addition, the spatial differences in NFC on earthquake risk due to the demographic composition of residents (which will decrease as time passes and infrastructure develops further and high levels of education become more common), NFC on earthquake risk will also rise after a quake in the area where it has been felt, indicating that spatial differentiation of NFC occurs. The examples in Figures 2-4 show that NFC rose dramatically after earthquakes, and people in the areas where quakes had occurred presented higher NFC on earthquake risk. The example in Figure 5 shows that the phenomenon continued in the long term as well; that is, the Moran's $I$ for $F_{i w}$ increased when $F_{i w}$ increased after a quake and an obvious spatial differentiation of NFC was observed. Along with this, earthquakes that occurred within the borders of China easily aroused Chinese NFC, while many large magnitude earthquakes aboard did not arouse Chinese NFC. This confirmed the previous view $[50,51]$. The distance in the spatial displacement and social relationship can affect the risk transmissibility, so the earthquake risk that people usually perceive is also limited by its location in space and interpersonal relationship. The weakening of subjective risk cognition caused by geographical distance reflects the risk discount in spatial dimension.

This study holds that there are three reasons for the difference of NFC on earthquake risk related to geography. One is the geographical characteristics of a given earthquake; because earthquakes are huge geophysical events, shaking is felt and losses are associated with the areas within a smaller distance from the epicenter, and people who experience 


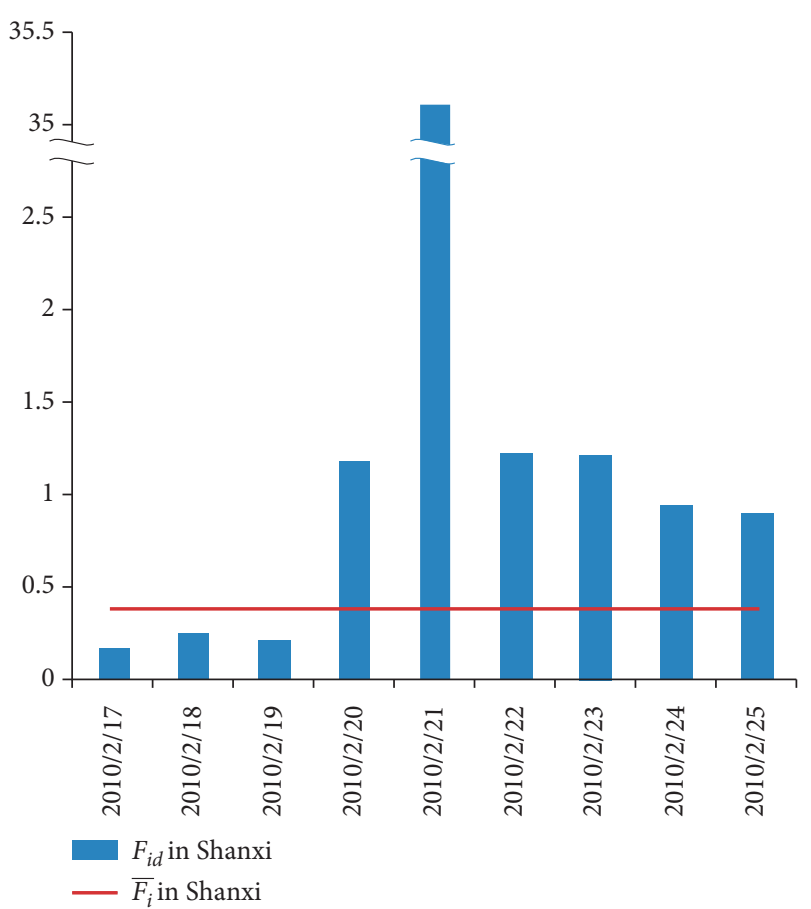

Figure 7: $F_{i d}$ in Shanxi before and after the Shanxi earthquake tumor.

strong tremors have a corresponding strong demand for more information. As the distance from the epicenter increases, people who feel little or no shaking have a weaker demand for information. The second reason is that it is becoming easier and quicker to gain and process information, as the development of Internet has released the acquisition of information from temporal and spatial constraints. After an earthquake, people across the country hear about news of the quake, including its location. Based on this, their personal geographical distance from the quake leads to different psychological distances. The closer the geographic distance, the closer the psychological distance and the higher the information requirement. The third reason is that when earthquakes occur, residents of that province or country feel close to it in terms of social distance, which may cause members of that community to perceive and evaluate risk in similar ways according to spatial, social, or other dimensions [64]. Because people feel close to earthquakes that occur within their own provinces or countries, those earthquakes cause more concern to those specific populations. In sum, after an earthquake, NFC on earthquake rises dramatically in the nation and exhibits spatial differentiation.

5.1.4. The Effect of Uncertainty on NFC. According to the theory of psychological distance, the higher the probability of event [65], the closer psychological distance. The dimension of uncertainty in psychological distance influences NFC on earthquake risk in two aspects: (1) the historical frequency of earthquakes and (2) the belief that earthquakes are predictable and that one will occur on a certain day [2].
The effects of these two aspects are both present in the research. The relationship between the historical frequency of earthquakes and NFC is shown in Table 1 and Figure 6, and the variations in NFC are caused by earthquake rumors in Figure 7.

As for NFC on earthquake risk in the long term, there were some obvious differences between the provinces, as shown in Figure 6. NFC was high in the western mountain regions and low in the east coast regions. This paper posits that if earthquakes are more likely to occur in certain places, then, for people who lived in these places and have had experienced more earthquakes, their psychological distance to quakes is closer in the uncertainty dimension and is closer to the quake [40], which causes differences in NFC to occur according to the region. Earthquakes frequently strike the Tibetan plateau, which could be the reason that the Tibet province had the highest NFC on earthquake in China, reaching a level of 0.802. In contrast, Guangdong, Guangxi, and Hunan provinces were less exposed to the risk of earthquakes, resulting in a relatively low NFC. Based on these findings, without regard to the municipalities (Beijing, Shanghai, and Tianjin), NFC on earthquake risk was positively related to the historical frequency of earthquakes $(r=0.76)$, such that a history of more frequent earthquakes leads to a higher level of NFC.

Earthquake rumors are the spread of unscientific and misleading information about earthquakes and this phenomenon occurs in part because of the maliciousness of those starting the rumors and in part because of the public's general ignorance of earthquake risk. In the example of the Shanxi earthquake rumor, on February 19th, a rumor began to circulate that an earthquake would occur two days later. By February 20th, the rumor had continued to simmer and the $F_{i d}$ had increased by 7 times. By February 21 st, $F_{i d}$ had increased by 35.1 times compared to February 20th. Looking at Figure 7, it can be found that $\mathrm{F}_{i d}$ curve was a "peakpattern," like those that occur with predictable disasters $[37,38,61]$, although no earthquake occurred. The appearance of this phenomenon was mostly likely due to the public's certainty about the immediate occurrence of an earthquake in their location, and this "certainty" decreased the psychological distance in all four dimensions, quickly raised the level of NFC on earthquake, and led to a large volume of information searching.

Due to the increase in NFC on earthquake risk and the time required for this to foment, the beginnings of an earthquake rumor might be detected through monitoring, that is, if a sharp rise in FSE occurs without an earthquake. Based on this information, the government and risk managers would have enough time to stop the spread of bad information, which may prevent social unrest.

5.2. Practical Implications for Risk Management. Because NFC on earthquake risk is variable, we suggest that the efficiency of risk communication be increased by considering the effects of psychological distance. (1) First is carrying out emergency exercises after quakes. After a quake, people have a closer temporal distance to the earthquake, a higher NFC, and 
take more action to acquire knowledge. Thus, carrying out emergency exercises directly after earthquake event instead of ordinary times will garner much better results. (2) Second is paying adequate attention not only to areas where earthquakes occur but also to the surrounding areas, especially where earthquakes are frequent. People in these areas have a closer psychological distance in the spatial and uncertainty dimensions and a higher NFC, so it is important to popularize the knowledge of earthquake risk and improve scientific understanding so that social problems caused by missing or incorrect information can be avoided. (3) Third is manipulating distance-related factors to increase the concreteness of risk communication, thereby influencing individuals' risk perceptions, behavioral intentions [40, 42], and NFC, which will develop their ability to obtain information and knowledge on earthquake risk. To achieve more effective risk communication, we suggest using sentence structures with a low-construal level (example: earthquakes can occur anywhere at any time) rather than sentences with a high-construal level (example: earthquakes rarely occur) to educate the public.

In addition, government and risk managers should monitor disaster information on the Internet, looking out for the spread of rumors and misinformation so that they can respond rapidly. If the Chinese government can detect FSE anomalies to find the beginnings of rumors, it may be able to dispel those rumors by spreading scientific information and satisfying the public's NFC on earthquake risk. Social unrest caused by rumor might be prevented, and the public's level of scientific knowledge on earthquake risk mitigation might even rise.

\section{Conclusions}

In this study, based on the Psychological Distance Theory, 3 hypotheses regarding NFC on earthquake risk in China were analyzed using search engine data from the Baidu index. It was found that temporal distance, spatial distance, and social distance influenced NFC on earthquake risk that was the closer the distance to an earthquake, the higher the NFC on earthquake risk. Probability distance's influence was not supported for the difference in social development. The last part of the paper presents suggestions for risk management based on these findings.

In prior studies, the data sources about applications of psychological distance were derived from psychological experiments $[46-49,66]$ and traditional questionnaire survey $[50,51]$. The available methods impose restrictions on the scales of time and space that can be studied. However, this paper used a new-type big data statistics mining data to analyze earthquake risk cognition need within wider spatial scale and longer time frame. Moreover, it extended the application of psychological distance theory to analyze risk cognition in the field of environmental health risk and probed into the influence rules to earthquake risk cognition need by temporal distance, spatial distance, social distance, and uncertainty.

Because the number of daily Internet users in each province of China could not be accessed, this paper matched annual data to daily data, which might affect the accuracy of the results. In future studies, it is better to obtain daily data or try to obtain similar data instead. Furthermore, the influence of other dimensions of psychological distance on earthquake risk cognition need can be further investigated. Moreover, in the future research, models can be used to analyze earthquake risk cognitive need, in which the impact factors can be demographic characteristics (gender, age, occupation, education, and income level), earthquake location, magnitude, time, historical earthquake frequency locally, and so on.

As the development of the society, economy, and education continues in the future, NFC of risk throughout society will increase. We believe that further study on the laws of NFC on risk will aid the development of effective risk communication plans that satisfy the public's need to acquire knowledge and reduce loss due to risk [67-95].

\section{Data Availability}

The data used to support the findings of this study are available from the corresponding author upon request.

\section{Conflicts of Interest}

The authors declare that there are no conflicts of interest regarding the publication of this paper.

\section{Acknowledgments}

This work was supported by the Liaoning Planning Fund Project of Philosophy and Social Science (no. L20CGL004), the National Natural Science Foundation of China (no. 41871162), and the Fundamental Research Funds for the Central Universities (no. N182410002-5 and N2011001).

\section{References}

[1] N. F. Pidgeon, "Risk assessment, risk values and the social science programme: why we do need risk perception research," Reliability Engineering and System Safety, vol. 59, pp. 5-15, 1998.

[2] D. J. Whitney, M. K. Lindell, and H. H. D. Nguyen, "Earthquake beliefs and adoption of seismic hazard adjustments," Risk Analysis, vol. 24, no. 1, pp. 87-102, 2004.

[3] J. T. Cacioppo, R. E. Petty, J. A. Feinstein, and W. B. G. Jarvis, "Dispositional differences in cognitive motivation: the life and times of individuals varying in need for cognition," Psychological Bulletin, vol. 119, no. 2, pp. 197-253, 1996.

[4] A. Bertrams and O. Dickhäuser, "High-school students' need for cognition, self-control capacity, and school achievement: testing a mediation hypothesis," Learning and Individual Differences, vol. 19, no. 1, pp. 135-138, 2009.

[5] I. Armaş, "Earthquake risk perception in Bucharest, Romania," Risk Analysis, vol. 26, no. 5, pp. 1223-1234, 2006.

[6] J. Krikelas, "Information-seeking behavior: patterns and concepts," Drexel Library Quarterly, vol. 19, no. 2, pp. 5-20, 1983.

[7] X. H. Guo, N. N. Zou, W. Y. Cheng et al., "Correlation between cognition need and information seeking behaviors," Chinese Journal of Medical Library and Information Science, vol. 5, pp. 16-20, 2014. 
[8] P. Williams-Piehota, J. Pizarro, S. A. Navarro Silvera, L. Mowad, and P. Salovey, "Need for cognition and message complexity in motivating fruit and vegetable intake among callers to the cancer information service," Health Communication, vol. 19, no. 1, pp. 75-84, 2006.

[9] P. Slovic, "Perception of risk," Science, vol. 236, no. 4799, pp. 280-285, 1987.

[10] R. J. Griffin, S. Dunwoody, and K. Neuwirth, "Proposed model of the relationship of risk information seeking and processing to the development of preventive behaviors," Environmental Research, vol. 80, no. 2, pp. S230-S245, 1999.

[11] D. J. Severtson, L. C. Baumann, and R. L. Brown, "Applying a health behavior theory to explore the influence of information and experience on arsenic risk representations, policy beliefs, and protective behavior," Risk Analysis, vol. 26, no. 2, pp. 353-368, 2006.

[12] M. L. Ybarra and M. Suman, "Help seeking behavior and the Internet: a national survey," International Journal of Medical Informatics, vol. 75, no. 1, pp. 29-41, 2006.

[13] J. Wang, N. Xiao, and H. R. Rao, "An exploration of risk information search via a search engine: queries and clicks in healthcare and information security," Decision Support Systems, vol. 52, no. 2, pp. 395-405, 2012.

[14] M. A. Winkleby, J. A. Flora, and H. C. Kraemer, "A community-based heart disease intervention: predictors of change," American Journal of Public Health, vol. 84, no. 5, pp. 767-772, 1994.

[15] K. Real, "Information seeking and workplace safety: a field application of the risk perception attitude framework," Journal of Applied Communication Research, vol. 36, no. 3, pp. 339-359, 2008.

[16] L. A. Kahlor, "An augmented risk information seeking model: the case of global warming," Media Psychology, vol. 10, no. 3, pp. 414-435, 2007.

[17] M. M. Turner, R. N. Rimal, D. Morrison, and H. Kim, “The role of anxiety in seeking and retaining risk information: testing the risk perception attitude framework in two studies," Human Communication Research, vol. 32, no. 2, pp. 130-156, 2006.

[18] D. Asai, Y. Sagata, and Y. Asano, On-Site Information Seeking Behaviors in Earthquake and Tsunami: CHI'13 Extended Abstracts on Human Factors in Computing Systems, Association for Computing Machinery, New York, NY, USA, 2013.

[19] T. D. Wilson, "Models in information behaviour research," Journal of Documentation, vol. 55, no. 3, pp. 249-270, 1999.

[20] C. C. Kuhlthau, "Inside the search process: information seeking from the user's perspective," Journal of the American Society for Information Science, vol. 42, no. 5, pp. 361-371, 1991.

[21] K. Viswanath and J. R. Finnegan, "The knowledge gap hypothesis: twenty-five years later," Annals of the International Communication Association, vol. 19, no. 1, pp. 187-228, 1996.

[22] B. Verplanken, "Need for cognition and external information search: responses to time pressure during decision-making," Journal of Research in Personality, vol. 27, no. 3, pp. 238-252, 1993.

[23] D. Fallows, Search Engine Use, Pew Internet \& American Life Project, New York, NY, USA, 2008.

[24] T. L. Tuten and M. Bosnjak, "Understanding differences in web usage: the role of need for cognition and the five factor model of personality," Social Behavior and Personality: An International Journal, vol. 29, no. 4, pp. 391-398, 2001.

[25] S. Y. Ho, "An exploratory study of using a user remote tracker to examine web users' personality traits," in Proceedings of the 7th International Conference on Electronic Commerce, pp. 659-665, ACM, Xi'an, China, 2005.

[26] J. Liu and X. Zhang, "The effect of need for cognition on search performance," Proceedings of the American Society for Information Science and Technology, vol. 45, no. 1, pp. 1-12, 2008.

[27] Y. Qu, P. F. Wu, and X. Wang, "Online community response to major disaster: a study of tianya forum in the 2008 sichuan earthquake: system sciences," in Proceedings of the HICSS'09 42nd Hawaii International Conference, IEEE, Waikoloa, HI, USA, 2009.

[28] P. M. Polgreen, Y. Chen, D. M. Pennock, and F. D. Nelson, "Using internet searches for influenza surveillance," Clinical Infectious Diseases, vol. 47, no. 11, pp. 1443-1448, 2008.

[29] B. M. Althouse, Y. Y. Ng, and D. A. T. Cummings, "Prediction of dengue incidence using search query surveillance," PLoS Neglected Tropical Diseases, vol. 5, no. 8, p. e1258, 2011.

[30] G. J. Milinovich, R. J. S. Magalhães, and W. Hu, "Role of big data in the early detection of ebola and other emerging infectious diseases," The Lancet Global Health, vol. 3, no. 1, pp. e20-e21, 2015.

[31] N. Li, G. Peng, Y. J. Su et al., "Research on the prediction of the number of AIDS cases based on baidu search data," in Proceedings of the Academic Conference on Business Management Based on Internet, pp. 450-454, Shanghai, China, 2012.

[32] Y. H. Yang, Q. Zeng, H. Zhao et al., "Hepatitis B prediction model based on Google trends," Journal of Shanghai Jiaotong University, vol. 33, no. 2, pp. 204-208, 2013.

[33] J. E. Shortridge and S. D. Guikema, "Public health and pipe breaks in water distribution systems: analysis with internet search volume as a proxy," Water Research, vol. 53, pp. 26-34, 2014.

[34] T. Xie, Z. Yang, S. Yang, N. Wu, and L. Li, "Correlation between reported human infection with avian influenza A H7N9 virus and cyber user awareness: what can we learn from digital epidemiology?" International Journal of Infectious Diseases, vol. 22, pp. 1-3, 2014.

[35] Y. Gu, F. Chen, T. Liu et al., "Early detection of an epidemic erythromelalgia outbreak using Baidu search data," Scientific Reports, vol. 5, p. 12649, 2015.

[36] J. Z. Ding, Relationship Study between Internet Data and Hand-Foot-And-Mouth Disease Incidence in Jiangsu Province, Southeast University, Nanjing, China, 2019.

[37] C. K. Chen, Z. Li, and Y. F. Sun, "Study on characteristics of disaster information transmission based on complex networks," Journal of Catastrophology, vol. 23, no. 4, pp. 126-129, 2008.

[38] K. L. Lee, R. J. Meyer, and E. T. Bradlow, "Analyzing risk response dynamics on the web: the case of hurricane katrina," Risk Analysis, vol. 29, no. 12, pp. 1779-1792, 2009.

[39] L. Wang and J. M. Jia, "Risk perception dynamics in unexpected disaster events: evidence from online search," Management Review, vol. 5, pp. 169-176, 2014.

[40] A. Spence, W. Poortinga, and N. Pidgeon, "The psychological distance of climate change," Risk Analysis, vol. 32, no. 6, pp. 957-972, 2012.

[41] N. Liberman and Y. Trope, "The psychology of transcending the here and now," Science, vol. 322, no. 5905, pp. 1201-1205, 2008.

[42] J. J Zheng, C. Z. Li, and C. Shao, "Impacts of decision framing and psychological distance on individual cooperative behavior," Management Review, vol. 29, no. 5, pp. 102-109, 2017. 
[43] N. Liberman, Y. Trope, and E. Stephan, "Psychological distance," Social Psychology: Handbook of Basic Principles, pp. 353-383, The Guilford Press, New York, NY, USA, 2007.

[44] L. Lian, Research on Psychological Distance of the Environmental Risk Perception, Harbin Institute of Technology, Harbin, China, 2013.

[45] C. J. Wakslak, Y. Trope, N. Liberman, and R. Alony, "Seeing the forest when entry is unlikely: probability and the mental representation of events," Journal of Experimental Psychology: General, vol. 135, no. 4, pp. 641-653, 2006.

[46] O. Svenson and G. Karlsson, "Decision-making, time horizons, and risk in the very long-term perspective," Risk Analysis, vol. 9, no. 3, pp. 385-399, 1989.

[47] S. Nicolaij and L. Hendrickx, "The influence of temporal distance of negative consequences on the evaluation of environmental risks," Human Decision Making and Environmental Perception, vol. 1, pp. 47-67, 2003.

[48] L. Hendrickx, A. Van den Berg, and C. Vlek, "Zorgen over morgen? de factor "tijd" in de evaluatie van milieurisico's (concern about tomorrow? the factor time in the evaluation of environmental risks," Milieu, Tijdschrift Voor Milieukunde, vol. 8, pp. 148-152, 1993.

[49] L. Hendrickx and S. Nicolaij, "Temporal discounting and environmental risks: the role of ethical and loss-related concerns," Journal of Environmental Psychology, vol. 24, no. 4, pp. 409-422, 2004

[50] Z. H. Shang, Z. H. Guo, C. H. Li, and Y. Y. Chen, "Comparative analysis of haze risk perception and its acceptability," Environmental Science and Management, vol. 45, no. 7, pp. 7-11, 2020.

[51] Z. H. Shang, X. H. Liang, C. H. Li, Z. H. Guo, K. Y. Gu, and Q. Mo, "Comparative analysis of public typhoon disaster risk perception based on psychological distance: taking zhanjiang city and zhuhai city as examples," Journal of Institute of Disaster Prevention, vol. 21, no. 4, pp. 66-74, 2019.

[52] K. Sun, L. Huang, B. L. Duan et al., "Analysis of public risk perception on earthquake," Journal of Safety and Environment, vol. 6, pp. 118-121, 2010.

[53] C. D. Xu, Q. Zhou, and Y. C. Yu, "Research on the public perception and responses to the disaster of the Ms80 wenchuan earthquake-stricken area a case study in Nanzheng in southern Shaanxi," Journal of Seismological Research, vol. 3, pp. 336-343, 2010.

[54] Y. Su, J. H. Xie, F. Y. Ma et al., "Influence of wenchuan earthquake to the public's disaster cognition in beijing," Journal of Seismological Research, vol. 34, no. 3, pp. 378-383, 2011.

[55] J. M. Jia, H. Q. Li, and C. M. Fan, "Comparative analysis of risk perceptions of people in severely and slightly affected areas," Management Review, vol. 20, no. 12, pp. 4-10, 2008.

[56] H. Q. Li, S. H. Wang, C. M. Fan et al., "Public fear and emergency management in sudden disasters," East China Economic Management, vol. 9, pp. 36-40, 2011.

[57] Y. Shani, E. R. Igou, and M. Zeelenberg, "Different ways of looking at unpleasant truths: how construal levels influence information search," Organizational Behavior and Human Decision Processes, vol. 110, no. 1, pp. 36-44, 2009.

[58] S. S. Ye and G. F. Zhai, "A review on seismic economic loss estimation,” Progress in Geography, vol. 6, pp. 684-692, 2010.

[59] M. Hao and J. B. Liu, "Review of study on urban earthquake prevention and disaster mitigation planning," Journal of Natural Disasters, vol. 17, no. 5, pp. 40-46, 2008.

[60] BAIDU, Index_Help [EB/OL], 2020, http://www.Baidu.com/ search/index_help.html.
[61] China Internet Network Information Center, $25^{\text {th }}$ Statistical Survey Report on Internet Development in China, China Internet Network Information Center, Beijing, China, 2010.

[62] P. A. Moran, "Notes on continuous stochastic phenomena," Biometrika, vol. 37, no. 1, pp. 17-23, 1950.

[63] F. Wang and Z. X. Yuan, "Discussion on public relations crisis of local government based on the earthquake rumor in Shanxi province," Plateau Earthquake Research, vol. 23, no. 2, pp. 60-62, 2011.

[64] A. Gattig and L. Hendrickx, "Judgmental discounting and environmental risk perception: dimensional similarities, domain differences, and implications for sustainability," Journal of Social Issues, vol. 63, no. 1, pp. 21-39, 2007.

[65] M. D. Henderson, K. Fujita, Y. Trope, and N. Liberman, "Transcending the "Here": the effect of spatial distance on social judgment," Journal of Personality and Social Psychology, vol. 91, no. 5, pp. 845-856, 2006.

[66] G. Böhm and H. R. Pfister, "Consequences, morality, and time in environmental risk evaluation," Journal of Risk Research, vol. 8, no. 6, pp. 461-479, 2005.

[67] G. O. Rogers, "The dynamics of risk perception: how does perceived risk respond to risk events?" Risk Analysis, vol. 17, no. 6, pp. 745-757, 1997.

[68] W. Kellens, R. Zaalberg, and P. De Maeyer, "The informed society: an analysis of the public's information-seeking behavior regarding coastal flood risks," Risk Analysis, vol. 32, no. 8, pp. 1369-1381, 2012.

[69] S. Li, G. Zhai, S. Zhou, C. Fan, Y. Wu, and C. Ren, "Insight into the earthquake risk information seeking behavior of the victims: evidence from songyuan, China," International Journal of Environmental Research and Public Health, vol. 14, no. 3, pp. 267-282, 2017.

[70] C. J. Sadowski, "An examination of the short need for cognition scale," The Journal of Psychology, vol. 127, no. 4, pp. 451-454, 1992.

[71] C. P. Haugtvedt and R. E. Petty, "Personality and persuasion: need for cognition moderates the persistence and resistance of attitude changes," Journal of Personality and Social Psychology, vol. 63, no. 2, pp. 308-319, 1992.

[72] C. Koch and E. Hayworth, "Examining the relationship between need for cognition and the muller-lyer illusion north American," Journal of Psychology, vol. 5, no. 2, pp. 249-256, 2003.

[73] S. Gülgöz, "Need for cognition and cognitive performance from a cross-cultural perspective: examples of academic success and solving anagrams," The Journal of Psychology, vol. 135, no. 1, pp. 100-112, 2001.

[74] J. T. Cacioppo and R. E. Petty, "The need for cognition," Journal of Personality and Social Psychology, vol. 42, no. 1, pp. 116-131, 1982.

[75] E. Beck, I. André-Poyaud, P.-A. Davoine, S. Chardonnel, and C. Lutoff, "Risk perception and social vulnerability to earthquakes in grenoble (French alps)," Journal of Risk Research, vol. 15, no. 10, pp. 1245-1260, 2012.

[76] S. Ainuddin, J. Kumar Routray, and S. Ainuddin, "People's risk perception in earthquake prone quetta city of baluchistan," International Journal of Disaster Risk Reduction, vol. 7, pp. 165-175, 2013.

[77] G. Marchionini, Information Seeking in Electronic Environments, Cambridge University Press, Cambridge, UK, 1997.

[78] P. Williams-Piehota, T. R. Schneider, J. Pizarro, L. Mowad, and P. Salovey, "Matching health messages to informationprocessing styles: need for cognition and mammography 
utilization," Health Communication, vol. 15, no. 4, pp. 375-392, 2003.

[79] P. Slovic, The Perception of Risk, Earthscan, London, UK, 2000.

[80] E. F. J. Huurne, R. J. Griffin, J. M. Gutteling et al., "Risk information seeking among U.S. And Dutch residents: an application of the model of risk information seeking and processing," Science Communication, vol. 31, no. 2, pp. 215237, 2009.

[81] B. Verplanken, P. T. Hazenberg, and G. R. Palenéwen, "Need for cognition and external information search effort," Journal of Research in Personality, vol. 26, no. 2, pp. 128-136, 1992.

[82] O. Kaynar and Y. Amichai-Hamburger, "The effects of need for cognition on internet use revisited," Computers in Human Behavior, vol. 24, no. 2, pp. 361-371, 2008.

[83] Y. Amichai-Hamburger, O. Kaynar, and A. Fine, "The effects of need for cognition on internet use," Computers in Human Behavior, vol. 23, no. 1, pp. 880-891, 2007.

[84] J. Ginsberg, M. H. Mohebbi, R. S. Patel, L. Brammer, M. S. Smolinski, and L. Brilliant, "Detecting influenza epidemics using search engine query data," Nature, vol. 457, no. 7232, pp. 1012-1014, 2009.

[85] X. T. Li, F. Liu, J. C. Dong et al., "Detecting China influenza using search engine data," Systems Engineering- Theoryw Practice, vol. 33, no. 12, pp. 3028-3034, 2013.

[86] Q. Fang, H. L. Kang, T. Li et al., "The prediction of dengue fever transmission risk in Guangzhou," Chinese Journal of Hygienic Insecticides \& Equipments, vol. 26, no. 3, pp. 265269, 2020.

[87] S. X. She, Q. Lu, and Z. Q. Wang, "Spatial discount model in environmental risk perception," Systems Engineering Theory \& Practice, vol. 32, no. 12, pp. 2712-2717, 2012.

[88] A. Todorov, A. Goren, and Y. Trope, "Probability as a psychological distance: construal and preferences," Journal of Experimental Social Psychology, vol. 43, no. 3, pp. 473-482, 2007.

[89] China Internet Network Information Center, $27^{\text {th }}$ Statistical Survey Report on Internet Development in China, China Internet Network Information Center, Beijing, China, 2011.

[90] China Internet Network Information Center, $29^{\text {th }}$ Statistical Survey Report on Internet Development in China, China Internet Network Information Center, Beijing, China, 2012.

[91] China Internet Network Information Center, $31^{\text {st }}$ Statistical Survey Report on Internet Development in China, China Internet Network Information Center, Beijing, China, 2013.

[92] China Internet Network Information Center, $33^{\text {rd }}$ Statistical Survey Report on Internet Development in China, China Internet Network Information Center, Beijing, China, 2014.

[93] China Internet Network Information Center, $35^{\text {th }}$ Statistical Survey Report on Internet Development in China, China Internet Network Information Center, Beijing, China, 2015.

[94] P. L. Curşeu, "Need for cognition and active information search in small student groups," Learning and Individual Differences, vol. 21, no. 4, pp. 415-418, 2011.

[95] G. L. Xi, F. Zhen, X. Y. Li et al., "Micro-participation in emergency management: urban management in micro-era," Planners, vol. 29, no. 3, pp. 37-42, 2013. 